
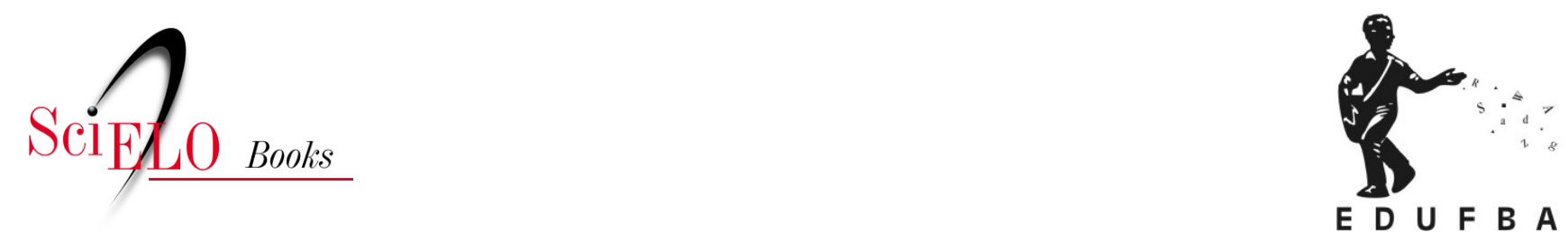

\title{
Antologia virtual de contos, casos e crônicas, com humor, escritos por mulheres no Brasil
}

\author{
Alba Valeria Tinoco Alves Silva
}

\section{SciELO Books / SciELO Livros / SciELO Libros}

SILVA, A.V.T.A. Antologia virtual de contos, casos e crônicas, com humor, escritos por mulheres no Brasil. In: Deus e o diabo no humor das mulheres: contos, casos e crônicas com humor escritos por mulheres [online]. Salvador: EDUFBA, 2015, pp. 169-175. ISBN: 978-85-232-1868-3.

https://doi.org/10.7476/9788523218683.0006.

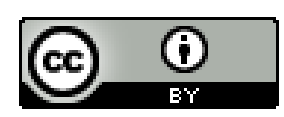

All the contents of this work, except where otherwise noted, is licensed under a Creative Commons Attribution 4.0 International license.

Todo o conteúdo deste trabalho, exceto quando houver ressalva, é publicado sob a licença $\underline{\text { Creative Commons }}$ Atribição 4.0.

Todo el contenido de esta obra, excepto donde se indique lo contrario, está bajo licencia de la licencia Creative Commons Reconocimento 4.0. 


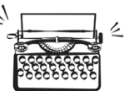

\section{Antologia virtual de contos, casos e crônicas, com humor, escritos por mulheres no Brasil}

A maioria das autoras escolhidas para figurar neste esboço de antologia ou antologia virtual é amplamente conhecida do grande público e, de certa forma, dispensa apresentação, como Clarice Lispector, Lygia Fagundes Telles, Hilda Hilst. Outras são familiares para um público mais especializado, por assim dizer, como é o caso de Nina Horta, conhecida por quem gosta de gastronomia; Carmen da Silva, por quem acompanha a trajetória do movimento de liberação feminina no Brasil; Elisa Palatinik, por quem gosta de humor, enfim.

Independente, porém, do seu grau de celebridade, foi reunido um conjunto mínimo de informações sobre cada uma delas, dizendo quem são essas mulheres, quando e onde nasceram, e onde os textos citados podem ser encontrados. Diz-se "mínimo", porque, como a linha de análise de textos deste trabalho é pelo viés dos temas e procedimentos de construção do humor encontrados no texto, não se acredita necessário fornecer dados biográficos extensos sobre as autoras, mas apenas situá-las no tempo e no espaço.

Como se explicou na introdução, a compilação de textos está sendo chamada de antologia virtual, porque, em virtude da impossibilidade de obtenção dos direitos autorais de todos eles, os textos não foram incluídos na íntegra. O que se buscou fazer foi obter 0 
endereço virtual de todos que já estão disponíveis na internet e incluí-los na lista que se segue.

Quanto aos textos, eles já foram analisados ao longo do capítulo 3 e não são mais comentados a partir daqui. O que se espera é que o humor que se julga neles presente seja evidente para outros olhos que não os da compiladora. E que a eventual leitura desses textos seja tão interessante e divertida quanto o foram sua compilação e análise.

\section{Sobre Autores}

Carmen da Silva (Rio Grande, RS; 1919-1985) - Jornalista, escritora e colaboradora em várias publicações brasileiras, a autora especializou-se em assuntos femininos. Publicou seu primeiro romance Septiembre, em 1958. O texto O feminismo é uma festa foi extraído de sua autobiografia Histórias híbridas de uma senhora de respeito, publicada pela Brasiliense, em 1984. Trata-se de um livro esgotado nas livrarias convencionais. O meu exemplar foi obtido através do sebo virtual: www.estantevirtual.com.br.

Clarice Lispector (Tchetchelnik, Ucrânia; 1920-1977) - Escritora e jornalista, iniciou sua carreira da década de 1940 com o romance Perto do coração selvagem. O texto O búfalo foi extraído de Laços de Família, seu primeiro livro de contos, publicado em 1960. A versão aqui citada foi retirada da edição do mesmo livro publicado pela Rocco, em 1998, mas o conto está disponível em http://claricelispector.blogspot.com.br/2007/11/o-bfalo.html. Outras das obras da autora podem ser encontradas no mesmo endereço virtual: http:// claricelispector.blogspot.com.br.

Cleise Mendes (Rio de Janeiro) - Escritora e professora de dramaturgia na Escola de Teatro da Universidade Federal da Bahia. Iniciou sua carreira na década de 1970, escrevendo contos e poemas para jornais e revistas e, desde então, tem produzido ininterruptamente textos dos mais variados gêneros, entre os quais se destacam 
37 peças de teatro já encenadas. O conto O convite está no livro de contos A terceira manhã, lançado em 2003.

Cora Coralina (Ana Lins do Guimarães Peixoto Brêtas) (Goiás; 1889-1985) - Poeta e contista, escrevendo desde a década de 1910 e tendo sido convidada por Monteiro Lobato para integrar a Semana de Arte Moderna de 1922, ela só se tornou conhecida do grande público em 1980, graças a uma carta de Carlos Drummond de Andrade elogiando o seu trabalho. O conto O lampião da Rua do Fogo está no livro Estórias da casa velha da ponte, publicado pela Global, em 2000. A versão aqui trabalhada foi retirada da edição de 2001. Este texto já está disponível no site www.releituras.com.br.

Danuza Leão (Espírito Santo; 1933) - Danuza Leão é uma celebridade desde os anos 1950, seja como manequim, irmã de Nara Leão ou esposa de Samuel Weiner. Como escritora, ela iniciou sua carreira em 1992 com o livro de dicas de savoir-viure, Na sala com Danuza. Desde então, ela tornou-se colaboradora regular do jornal Folha de S. Paulo, de cuja edição de 13 de janeiro de 2008, a crônica É bom se sentir em casa foi compilada.

Elisa Palatinik (Rio de Janeiro; 1962) - Começou sua carreira como escritora de humor em 1988, tendo atuado como colunista de jornais como $O$ Globo e redatora de programas de humor como o Chico Anísio Show e Sai de baixo, da Rede Globo. Considerada um dos destaques do humor da sua geração, Elisa é elogiada pelos humoristas Nani e Marcelo Madureira, do grupo Casseta e Planeta, que a considera o Woody Allen das Laranjeiras. O seu texto foi retirado do site www.releituras.com.br.

Eneida de Moraes (Belém, PA; 1904) - Formada em Odontologia, deixou o consultório para se tornar colaboradora em jornais e revistas e foi uma das mais profundas conhecedoras do carnaval brasileiro. Militante política, foi presa em 1935 e levada à Casa de Correção do Rio, onde, também por ideais políticos, encontrava-se o escritor Graciliano Ramos, que acabou por citá-la em Memórias do Cárcere. A crônica Conversas de mulher faz parte do livro Aruanda, 
publicado pela José Olympio, em 1957, e foi incluída nesta antologia virtual através do site www.releituras.com.br.

Hilda Hilst (Jaú, SP, 1930 - Campinas, SP, 2004) - Da poesia ao teatro, das edições bilíngues às páginas de jornal, do cômico ao trágico, da obscenidade à erudição, Hilda Hilst enveredou por quase todas as vertentes literárias. Iniciou sua carreira na década de 1950 com os livros Presságio (1950) e Balada de Alzira (1951). A crônica Como se e um brejeiro escoliasta... foi retirada do livro Cascos \& carícias, de 1997, volume de textos que saíram no jornal Correio Popular, de 1992 a 1995.

Leila Ferreira (Araxá, MG) - Jornalista, apresentadora e entrevistadora do programa Leila Entrevista, colunista da revista Marie Claire e escritora, autora dos livros Leila entrevista - bastidores e mulheres - por que será que elas..., lançado pela Globo em 2007, do qual foi retirado o texto Mulheres... por que será que elas... precisam de vinte e seis tipos de xampu?.

Lúcia Carvalho (São Paulo, SP; 1962) - Arquiteta e cronista, tem crônicas publicadas no livro Buscando o seu mindinho - um almanaque auricular, do escritor Mário Prata, lançado pela Editora Objetiva, em 2002, e no livro Espaços e pessoas, publicado pelo MEC. O texto A máquina foi retirado do site www.releituras.com.br.

Lygia Fagundes Telles (São Paulo, SP; 1923) - Escritora, ela lançou seu primeiro livro de contos Porão e sobrado ainda como Lygia Fagundes, em 1938, numa edição financiada por seu pai. Como Lygia Fagundes Telles, ela lança Praia viva, outro volume de contos, em 1944. O conto Pomba e namorada ou uma história de amor foi publicado em Seminário de ratos, de 1977, e depois republicado na antologia O papel do amor, de 1979. A versão do conto para esta antologia foi compilada no volume dedicado à autora da coleção Literatura Comentada, de 1980. Encontra-se na internet uma deliciosa versão do conto, narrado pela atriz Lilian Lemmertz, disponível em: http:// youtu.be/PuDixGQOMUM. 
Marcia Denser (São Paulo) - Jornalista, publicitária, editora, trabalhou na Salles, Folha, Interview e Vogue. Atuou como colunista literária da revista Nova, organizou duas coletâneas de contos eróticos escritos por mulheres: Muito prazer: contos eróticos femininos (1982) e O prazer é todo meu: contos eróticos femininos (1984). Como escritora, publicou seu primeiro livro, Tango Fantasma, aos 23 anos. O conto O vampiro da Alameda Casabranca faz parte do seu livro Diana Caçadora, editado pela Global, em 1986. Ele foi retirado da antologia Os cem melhores contos brasileiros do século, publicada em 2001. O conto está também disponível em: www.releituras.com.br.

Martha Medeiros (Porto Alegre, RS; 1961) - Fez sua carreira profissional na área de Propaganda e Publicidade, tenho trabalhado como redatora e diretora de criação em várias agências de Porto Alegre. Desde que passou a dedicar-se à literatura, tem atuado como cronista e colunista de publicações e sites brasileiros, como o jornal Zero Hora, a revista Época e o site Almas Gêmeas. O livro Strip-Tease, de 1985, foi a primeira publicação de seus trabalhos. O conto escolhido para figurar neste trabalho foi publicado no livro Trem-bala, em 2002, e foi extraído do site www.releituras.com.br.

Nina Horta (Minas Gerais) - Pós-graduada em Filosofia da Educação na USP, é dona do bufê Ginger em São Paulo e colabora, desde 1987, para a seção de Gastronomia do jornal Folha de S. Paulo. Suas crônicas foram reunidas no volume Não é sopa: crônicas e receitas de comida, pela Cia. das Letras, 1995.

Patricya Travassos (Rio de Janeiro, RJ) - Carioca, nascida em Ipanema, na época da bossa-nova, Patricya Travassos começou a carreira no grupo de teatro Asdrúbal Trouxe o Trombone e hoje atua em teatro e televisão, sendo apresentadora do programa Alternativa Saúde no canal GNT. Além de escrever para a televisão, teatro, cinema, também compõe letras musicais. É autora dos livros Esse sexo é feminino e Alternativas de A a $\mathrm{Z}$. Os contos de Patricya que figuram neste trabalho foram retirados do livro Monstra e outras crônicas da revista Marie Claire, em 2006. 
Rachel de Queiroz (Fortaleza, CE, 1910 - Rio de Janeiro, RJ, 2003) Escritora e jornalista, publica seu primeiro romance, O Quinze, em 1930. Em 1977, torna-se a primeira mulher a ser eleita para a Academia Brasileira de Letras. A crônica Viagem de bonde é datada de 1953. Incluída no livro O melhor da crônica brasileira, de 1997, a versão aqui presente foi retirada do site www.releituras.com.br.

Sônia Coutinho (Bahia, 1939) - Contista premiada e traduzida para diversas línguas, romancista e tradutora. O conto Darling, ou do amor em Copacabana faz parte do volume de contos Uma certa felicidade, publicado pela Rocco, em segunda edição, em 1994.

Vera Pacheco Jordão (1910-1980) - Há duas informações sobre o local de nascimento da autora. Na Antologia do Humorismo e Sátira, de Magalhães Jr. e no site www.releituras.com.br, diz-se que ela nasceu em São Paulo e tornou-se carioca por opção. No livro de Heloísa Buarque, Ensaístas brasileiras, seu local de nascimento seria Paris. Seja como for, ela foi jornalista e professora, com especialização em literatura norte-americana pela Universidade de Harvard. Dedicou-se à literatura infantil, à crítica literária e de arte e às crônicas de viagem, tema do texto Sabiás e rouxinóis, publicada em o Cruzeiro e incluído na primeira edição da Antologia do Humorismo e Sátira, organizada por Magalhães Jr, datada de 1957, de cuja segunda edição a versão aqui incluída foi retirada. O texto está também disponível em: www.releituras.com.br.

Zulmira Ribeiro Tavares (São Paulo, SP; 1930) - Professora de cursos de pós-graduação na Escola de Comunicação e Artes da Universidade de São Paulo e pesquisadora das áreas de cinema e televisão, é também escritora de poesia e contos, tendo sido agraciada com o prêmio Revelação em Literatura da APCA em 1974 pela sua obra Termos de Comparação, onde o conto A curiosa metamorfose pop do senhor Plácido está incluído. Para esta antologia, o conto foi retirado da antologia organizada por Flávio Moreira da Costa, Os 100 melhores contos de humor da literatura universal, de 2001.

Anônima - A narradora anônima representa aqui as contadoras de histórias: avós, tias, cozinheiras, vizinhas, que, com o dom 
e o prazer da narrativa oral, têm, por gerações, encantado ouvintes de todas as idades. A história escolhida para figurar no trabalho, Artes de Branca-Flor, costumava ser contada aos netos por minha avó paterna, Maurina. Sua versão escrita foi retirada de Lendas e fábulas do Brasil, publicada pela Cultrix, em 1964. Este texto está disponível em dois sites. Uma versão oral, narrada por dois contadores de histórias, encontra-se em: http://youtu.be/TPJhB4Kb6yA. Uma versão escrita está em: http://www.jangadabrasil.com.br/maio33/ im33050c.htm. 